\title{
Escolas/Classes Multisseriadas do Campo: reflexões para a formação docente
}

\begin{abstract}
Natacha Eugênia Janata'
Edson Marcos de Anhaia'

'Universidade Federal de Santa Catarina (UFSC), Florianópolis/SC - Brasil

RESUMO - Escolas/Classes Multisseriadas do Campo: reflexões para a formação docente. $\mathrm{O}$ artigo trata da formação de professores que atuam nas escolas/classes multisseriadas do campo, tendo como base os princípios da Educação do Campo, em contraposição ao pacote educacional denominado como Programa Escola Ativa, implementado no Brasil em 1997. Inicia abordando o contexto dos anos 1990, com as políticas neoliberais que atingem a educação no país e da qual decorrem, entre outros, o fechamento das escolas/classes multisseriadas no campo. Aborda o Programa Escola Ativa e sua vinculação às políticas neoliberais no país, discorrendo sobre os princípios da Educação do Campo, finalizando com indicativos para a formação de professores de escolas/classes multisseriadas.

Palavras-chave: Educação do Campo. Escolas Multisseriadas. Neoliberalismo. Organismos Internacionais.
\end{abstract}

ABSTRACT - Rural Schools with Multigrade Classes: reflections for teacher's graduation. This article deals with the graduation of teachers working in rural schools with multigrade classes, based on the principles of rural education, as opposed to the educational package termed as Programa Escola Ativa, implemented in Brazil in 1997. It starts addressing the context of the 1990s, with neoliberal politics affecting education in the country and which arise, among others, the closing of rural schools with multigrade classes. Addresses the Programa Escola Ativa and its link to neoliberal politics in the country, discussing the principles of the rural Education, ending with key indications to the teacher's training in schools with multigrade classes.

Keywords: Rural Education. Multigrade Schools. Neoliberalism. International Organizations.

Educação \& Realidade, Porto Alegre, v. 40, n. 3, p. 685-704, jul./set. 2015. 685 http://dx.doi.org/10.1590/2175-623645783 
As escolas/classes multisseriadas ${ }^{1}$ são uma forma de organização escolar em que alunos de diferentes idades e tempo ou níveis de escolarização (o que conhecemos por série) ocupam uma mesma sala de aula, sob a responsabilidade de um mesmo professor. Presentes no contexto do campo, as escolas/classes multisseriadas são frutos de um período histórico que nos remete ao Brasil colônia, com as professoras leigas e ambulantes que davam aulas aos filhos dos donos das terras e por consequência aos filhos dos seus trabalhadores, após a expulsão dos jesuítas do país em 1759.

Em 1827, com a promulgação da Lei Geral do Ensino, pelo governo imperial, adotou-se o ensino mútuo, ou por meio de monitoria, em que alunos considerados mais avançados na aprendizagem ensinavam os mais novos e/ou em níveis anteriores. Denominado como Método Lancasteriano, foi importado da Inglaterra pelo Estado e assumido como um avanço na educação brasileira do século XIX (Santos; Moura, 2010; Hage, 2010).

Com a República (1889), foram criados os Grupos Escolares e com eles se inicia a adoção do modelo seriado de escolarização, que se popularizou inicialmente e principalmente nas cidades, pois como afirmam Santos e Moura, nas vilas e povoados e na zona rural "permanecem funcionando as escolas isoladas, multisseriadas" (Santos; Moura, 2010, p. 41) para atender questões de ordem demográfica e densidade populacional, fato que ainda permanece. Tal processo segue ocorrendo ao longo de 1900, passando por uma expansão e interiorização dos Grupos Escolares.

A partir de 1990 ocorreu uma nova reconfiguração econômica no Brasil, incidindo em uma reestruturação da organização administrativa educacional, com a municipalização do ensino, sobretudo dos anos iniciais, entre outros aspectos. Foi um período marcado pelas consequências do fim da ditadura militar (1984), concomitante a adoção das políticas neoliberais. No contexto do campo, como de todo o país, no fim dos anos 1980 e início dos anos 1990 houve uma reascensão dos movimentos sociais, com o fortalecimento da organização dos trabalhadores do campo e de suas lutas, tendo como consequência a constituição do Movimento dos Trabalhadores Rurais Sem Terra (MST) e do Movimento dos Atingidos por Barragens (MAB) ${ }^{2}$, entre outros.

A partir da promulgação da Lei de Diretrizes e Bases da Educação Nacional, LDB No 9394/96, viveu-se um momento de fechamento das escolas/classes multisseriadas do campo, com a nucleação nas sedes dos municípios, advinda da municipalização e da adoção das reformas neoliberais que atingiram também a educação. Ao mesmo tempo, houve a constituição da Educação do Campo como fruto das lutas dos movimentos sociais do campo pelo acesso às políticas públicas de educação aos trabalhadores que produzem sua vida neste espaço.

Diante desse contexto, em que consistem as políticas neoliberais dos anos 1990 e como se associam à constituição da Educação do Cam- 
po? Como as formulações que envolvem a Educação do Campo podem auxiliar a problematizar a formação docente voltada às especificidades das escolas/classes multisseriada?

Esses são os questionamentos sobre os quais nos debruçamos neste texto, buscando contribuir para o avanço e o aprofundamento teórico, numa perspectiva crítica, da produção acerca da Educação do Campo, especificamente no que tange a organização das escolas/classes multisseriadas no Brasil ${ }^{3}$.

\section{Políticas Públicas Educacionais Brasileiras nos Anos 1990: ajustes neoliberais}

Os anos de 1990 marcaram uma nova forma de organizar a política educacional em todo o mundo, especialmente nos países emergentes, como o Brasil. Naquele período fortalecia-se uma perspectiva de Estado minimalista, ou nas palavras de Sader (1999) um Estado Mini-Max: máximo para o capital e mínimo para o trabalho. As políticas internacionais começaram a visar a contenção de gastos sociais, ampliando as possibilidades de investimento na economia capitalista ${ }^{4}$.

Como panaceia a todos os problemas levantados naquele período, a educação ganha centralidade, especialmente para equacionar os problemas decorrentes das desigualdades sociais. Um dos princípios das mudanças em processo era a utilização da educação para alcançar a equidade social. O marco das políticas educacionais nos anos 1990 foi a Conferência Mundial sobre Educação para Todos ${ }^{5}$, realizada na cidade de Jomtien, Tailândia. Naquela oportunidade, governantes, organizações não-governamentais e, principalmente, empresários, reuniram-se para elaborar estratégias que atendessem as demandas neoliberais para a educação.

Ao lado do Estado, outras organizações são chamadas a realizar essa tarefa social, pois o que está em risco segundo o diagnóstico dos organismos multilaterais é, nada mais nada menos, que a paz mundial! Paz necessária a ser assegurada pelo investimento que todos os países devem despender na educação. Essas mesmas formulações vão estar presentes nos documentos gerados por uma avalanche de seminários realizados no Brasil, após o de Jomtien (Shiroma; Moraes; Evangelista, 2004, p. 61).

Importa destacar que o resultado desta conferência foi expresso em um documento cujo conteúdo retratou os principais desafios da educação para a entrada no século XXI. Dentre os desafios, destacam-se a erradicação do analfabetismo e o foco na aprendizagem. Observados apenas por este prisma, tais desafios parecem atender as demandas sociais da população, visto que a qualidade na educação passa, necessariamente, pela efetivação da função social da escola e ampliação da 
oferta educacional. No entanto, basta uma leitura mais atenta do próprio documento para destacarmos objetivos não tão evidentes assim.

A participação das organizações não-governamentais causa impacto considerável na insurgência do chamado terceiro setor que viria a ocupar lugar de destaque no cenário educacional brasileiro. Na reforma do Estado brasileiro, iniciada ainda nos anos 1990 sob o comando do então ministro da Administração e Reforma do Estado, Bresser Pereira, apontava-se a necessidade de aproximações entre as instituições escolares e as organizações não-governamentais, que assumiriam, em muitos casos, o papel do Estado na administração da educação. Outro objetivo velado foi a própria participação do setor privado na educação. Com o termo equidade buscou-se fortalecer o princípio da participação de todas as esferas da sociedade, tanto é verdade que o próprio slogan da conferência era Educação para Todos, leia-se: participação das esferas não-governamentais e privadas na educação.

O foco das políticas educacionais passa a ser a escola e o processo de escolarização. Os processos gerenciais de gestão são fortalecidos sob a justificativa da morosidade da educação pública comandada pelo Estado, ou sua ineficácia e, portanto, deveriam criar uma nova organização das escolas, relacionada às novas exigências neoliberais de desresponsabilização do Estado. Passaram a ser eficazes as escolas que adotavam mecanismos de gerenciamento da gestão, implicando na política do fazer mais com menos, ser mais eficiente e eficaz com menos investimento do Estado. Para isso, o setor privado conclamou a sociedade a ser parceira no financiamento da educação $0^{6}$.

Nos anos de 1990 a educação passou a ser orientada por políticas neoliberais tendo os organismos internacionais como os principais responsáveis por garantir que as metas e objetivos propostos fossem executados. Não que antes estivessem despreocupados com a educação, mas é neste período que organismos com finalidades diferenciadas entre si se unem em torno de objetivos comuns. UNESCO, Banco Mundial, UNICEF e CEPAL (Comissão Econômica para a América Latina e Caribe) juntaram-se em prol da educação para o século XXI. Um importante evento que demarcou as bases para o conteúdo da Conferência de Jomtien foi o PROMEDLAC V (V Reunião do Comitê Regional Intergovernamental do Projeto Principal de Educação para a América Latina e Caribe), demarcando já muito antes, final da década de 1970 e início de 1980, a crescente preocupação com as políticas educacionais. O principal objetivo desta reunião era definir como eixo tanto para o crescimento econômico quanto para a equidade social, a incorporação de conhecimentos no processo produtivo, vinculando-os fortemente à educação e profissionalização (Shiroma; Moraes; Evangelista, 2004).

As políticas neoliberais resultantes da união entre diferentes organismos internacionais estabelecem um conjunto de ações nos países tanto de economia avançada como nos países emergentes, como o caso do Brasil. Essas ações tiveram influência substancial nos processos 
educativos e nas legislações educacionais. Segundo Shiroma, Moraes e Evangelista (2004) o novo paradigma, voltado à produtividade do mercado demandava requisitos diferenciados de educação geral e qualificação profissional dos trabalhadores para atender as novas demandas. Disseminou-se a ideia de que para sobreviver à concorrência do mercado, para conseguir ou manter um emprego, para ser cidadão do século XXI, seria necessário dominar os códigos da modernidade?

A UNESCO foi um dos principais organismos internacionais que responderam ao desenvolvimento da educação. Nos anos 1990 esteve à frente da elaboração de muitos documentos que serviram de apoio à implementação das políticas educacionais nos países periféricos. Apoiada nas conclusões sobre o futuro da educação mundial, promovidas a partir da Conferência de Jomtien, expandiu conceitos como competências e educação não-formal, além de ter defendido preceitos como responsabilização de setores privados e não-governamentais para com a educação.

Um dos principais, senão o principal documento, produzido por este organismo internacional foi Educação: um tesouro a descobrir, mais conhecido como relatório Delors. Organizado pelo francês Jacques Delors, o documento assume um tom prescritivo e claramente vinculado aos preceitos neoliberais de educação. Especialmente arquitetado sob quatro pilares, Delors afirma que o objetivo da educação deva estar voltado à formação do cidadão do século XXI.

A educação ganha responsabilidades como o fortalecimento de uma cultura de paz, a ampliação de atitudes democráticas, a tolerância e a coesão social. Os novos desafios da educação para o século XXI devem estar atrelados a novos aprendizados, que se desenvolveriam por toda a vida. São os quatro pilares da educação: aprender a conhecer; aprender a fazer; aprender a viver juntos; aprender a ser ${ }^{8}$. Estes pilares são considerados modelos de desenvolvimento da educação, objetivos a serem alcançados por todas as instituições escolares. Tornam-se competências que o aluno deve adquirir caso queira se adequar às novas exigências educacionais para o século XXI ${ }^{9}$. A educação ao longo da vida apareceu como possibilidade do sujeito adquirir competências necessárias para atividades laborais futuras, aprendendo a lidar com as incertezas do mundo do trabalho e com a crise do desemprego.

Outro organismo internacional responsável por consolidar um projeto de educação para o século XXI foi a CEPAL. Ao produzir o documento chamado Transformación productiva con equidad recomendou que os países da região investissem em reformas dos sistemas educativos para adequá-los a ofertar conhecimentos e habilidades específicas requeridas pelos sistemas produtivos. Ficando evidente a vinculação das reformas com a necessidade de expansão ou adaptação do mercado, o que se buscava construir era uma cidadania moderna baseada na competitividade. 
Na esteira destas recomendações, o Brasil iniciou profundas alterações nas políticas de Estado para a educação. Com a criação do MARE (Ministério da Administração e Reforma do Estado), pretendeu-se estabelecer novas relações entre Estado e educação sob a justificativa de ineficiência do mesmo em gestar as políticas sociais. O principal objetivo com a criação deste ministério já no primeiro mandato de Fernando Henrique Cardoso era tornar a educação um serviço vinculado à iniciativa privada. O ministro do MARE, Bresser Pereira, defendia que a educação era um serviço a ser oferecido em regime de quase mercado, quer dizer: a educação deveria continuar pública, porém sob controle da iniciativa privada, ou de princípios desta iniciativa, como a ampla participação dos pais e comunidade no financiamento da educação. Segundo Bresser Pereira era preciso guiar a Reforma de Estado às proposições que promovessem a escola a uma instituição pública não-estatal, ficando entre o Estado e o mercado.

No entanto, após anos da Reforma ter ocorrido tornava-se evidente que seus objetivos de melhoria da qualidade educacional não logravam os resultados esperados. Havia, portanto, a proposição de Reformas educacionais defendidas pela CEPAL chegado a uma barreira instransponível. Novos documentos foram elaborados, considerando as experiências que não atingiram os resultados esperados e avançando para novas proposições que justificassem os fracassos dos primeiros anos de Reforma.

Nesse sentido, esses documentos cumprem uma dupla missão: 'diagnosticar' para corrigir os desvios, realinhando as agendas educacionais locais em função dos ajustes propostos pelas agências que as patrocinam e, apresentar legitimações que reafirmem suas proposições não apenas como sendo as melhores, mas também as mais justas (Campos, 2005, p. 02).

Outro importante organismo internacional que se juntou aos demais em prol da educação para o século XXI foi o Banco Mundial. Inicialmente sua criação se deu principalmente para prestar serviços de assistência técnica e financeira aos países periféricos. No caso brasileiro, a instituição tem prestado serviços de financiamento a projetos de infraestrutura desde os anos 1940, sendo que a partir dos anos de 1970 destaca-se como a principal fonte financiadora de ações sociais em todo o mundo. O principal montante de recursos para investimentos sociais financiados está na saúde e na educação.

Todavia, a participação do Banco Mundial no financiamento da educação não se limitou ao envio de recursos. Com sofisticados mecanismos de controle, o financiamento só vem se dando com uma série de condicionalidades, especialmente voltadas à afirmação e implementação da perspectiva educacional defendida pela instituição, que não foge a perspectiva apresentada aqui como fruto das reformas educacionais nos anos de 1990 (Fonseca, 1998).

690 Educação \& Realidade, Porto Alegre, v. 40, n. 3, p. 685-704, jul./set. 2015. 
Observando as atuais políticas desenvolvidas pelo Banco Mundial para a educação, destacam-se aquelas relacionadas à formação/ profissionalização de professores, as relacionadas à melhoria dos prédios escolares e, principalmente, as que focalizam a escola como núcleo de gestão. A Educação Básica como no início dos anos 1990, continua a ser a modalidade de ensino privilegiada e não por acaso. $\mathrm{O}$ anúncio da educação como meio para combater a pobreza ganha destaque no discurso desenvolvido em grande parte dos documentos que visavam recomendações para o setor educacional.

A resposta do Banco é cristalina: a educação, especialmente a primária e a secundária (educação básica), ajuda a reduzir a pobreza aumentando a produtividade do trabalho dos pobres, reduzindo a fecundidade melhorando a saúde, e dota as pessoas de atitudes de que necessitam para participar plenamente na economia e na sociedade (Shiroma; Moraes; Evangelista, 2004, p. 75).

É elementar que as ações do Banco Mundial não visavam combater a pobreza, senão criar paliativos aos problemas que se tornaram agudos e estruturais ao modelo econômico capitalista. Das ações destacadas pelos organismos internacionais, fica evidente que, mesmo com distinções, o projeto original era dar continuidade ao avanço das ações capitalistas de regulação no país.

\section{As Políticas Educacionais dos Anos 1990 e as Escolas/ Classes Multisseriadas do Campo}

Podemos afirmar que o processo de fechamento das escolas do campo, prioritariamente as multisseriadas, e a adoção do transporte escolar como forma de atendimento aos trabalhadores do campo foi uma decorrência do avanço das políticas neoliberais dos anos 1990 explicitadas.

Os preceitos de gerenciamento na gestão educacional, que envolvem a eficiência e a eficácia, impulsionaram medidas de economia nos cofres públicos. Embora a nucleação tenha ocorrido sob o argumento de elevação da qualidade do ensino com a concentração dos alunos e a separação em turmas seriadas, de acordo com as idades e níveis de escolarização, isso não se verificou. O que aconteceu foi uma redução no investimento na educação dos trabalhadores do campo e a substituição das escolas/classes multisseriadas pelo transporte escolar, de condição precária, trafegando em estradas mal conservadas. Daí conclui-se que esse processo teve como motivador central o financiamento da educação, desconsiderando as questões pedagógicas, sociais e culturais, sobretudo, reafirmando os interesses do capital na gestão da educação pública brasileira, sob a pecha das reformas neoliberais.

Mesmo com o intenso processo de nucleação vivido nesse período, ainda existe no território nacional, segundo dados da Secretaria de

Educação \& Realidade, Porto Alegre, v. 40, n. 3, p. 685-704, jul./set. 2015. 
Educação Continuada, Alfabetização e Diversidade e Inclusão - (2013), mais de 50 mil escolas multisseriadas no campo. Essa expressiva quantidade traz à tona a necessidade de estabelecer políticas de formação de professores voltadas ao atendimento dessa especificidade pedagógica.

Neste aspecto, destaca-se que foi no bojo das reformas neoliberais que o Brasil em 1997, seguindo orientação do Banco Mundial, implementou o Programa Escola Ativa para a formação dos professores de escolas multisseriadas do campo, como destaca Gonçalves:

O Programa Escola Ativa (PEA) foi implementado no Brasil a partir de 1997, no marco de um convênio com o Banco Mundial (BM), com o objetivo de melhorar o rendimento dos alunos de classes multisseriadas rurais. Para tanto focalizava dois vértices: a formação de professores e a melhoria da infraestrutura das escolas. Foi elaborado a partir das experiências do Programa Escuela Nueva (PEN), desenvolvida na Colômbia na década de 80 do século anterior. Ao longo dos anos 1990, o PEN constituía-se como um modelo para a educação no meio rural (Gonçalves, 2009, p. 38).

Segundo Gonçalves (2009), o programa constitui-se como um pacote educacional para a formação continuada de professores, executado inicialmente no Nordeste brasileiro e, com o tempo se estendendo para todo o território brasileiro. Em 1998 o programa passou a ser apoiado pelo Fundo de Fortalecimento da Escola (FUNDESCOLA) ${ }^{10}$. Segundo dados da Secretaria de Educação Continuada, Alfabetização e Diversidade $^{11}$ (2008), em 2007 o programa já estava sendo realizado nas regiões Norte, Nordeste e Centro Oeste em mais de dez mil escolas.

Por suas características há clara e direta associação às políticas neoliberais adotadas no Brasil a partir dos anos 1990. Desde o financiamento por agências multilaterais, até as questões de ordem pedagógica, que trazem a perspectiva do aprender a aprender para o ensino nas escolas/classes multisseriadas do campo, o Escola Ativa configura-se como um contraponto ao que os movimentos sociais do campo vêm produzindo no sentido da Educação do Campo, como afirma Ribeiro (2011).

Em sua continuidade, sobretudo após 2007, houve modificações no programa, após diversas críticas, como afirmam Gonçalves, Antunes-Rocha e Ribeiro (2010, p. 51):

Em 2008, com o término do Fundescola, o PEA é transferido para a recém criada Coordenação Geral de Educação do Campo (CGEC), localizada na Secretaria de Educação Continuada, Alfabetização e Diversidade (SECAD). Nesse espaço o PEA encontra-se diante da necessidade de rever sua trajetória como pacote educacional, pois a CGEC expressava uma proposta de política pública construída pelo envolvimento concreto de diferentes sujeitos, situa- 
dos em diferentes lugares da dinâmica social. A CGEC foi criada a partir da luta de movimentos sociais, universidades, organizações não governamentais e religiosas no contexto da Articulação Por Uma Educação do Campo. A Articulação estava enraizada em uma proposta político-pedagógica construída por meio de diálogo com os sujeitos envolvidos na luta pelos direitos fundamentais de ampliação do acesso, da permanência e do direito à escola pública de qualidade no campo (Gonçalves; Antunes-Rocha; Ribeiro, 2010, p. 51).

Quando o PEA foi realocado institucionalmente na SECAD/CGEC, passou-se por um processo de reestruturação, tencionado em grande medida pelos movimentos sociais do campo e instituições que historicamente constituíram a Educação do Campo. Essas tensões fizeram com que houvesse a ampliação do programa para todas as regiões do país. Ainda que não tivessem ocorrido alterações significativas no escopo teórico-metodológico do PEA, abriram-se possibilidades na medida em que as universidades ${ }^{12}$ passaram a elaborar os projetos de formação de professores no âmbito de seus estados, direcionando-os em conformidade com os princípios assumidos pela instituição.

Os princípios fundamentais para a formação de professores que atuam em escolas/classes multisseriadas do campo, a nosso ver, precisam articular-se com a Educação do Campo, compreendendo-a como acúmulo da luta dos trabalhadores do campo, que percebem a importância e a necessidade de ampliá-la para além do acesso a terra, entendendo que são necessárias mudanças mais radicais na estrutura da sociedade. A educação vai sendo incorporada, gradativamente, como fundamental nesse processo. Coloca-se na agenda nacional o campo brasileiro em seus diferentes aspectos, com ênfase na educação e na discussão de um projeto de sociedade, denunciando a precariedade das escolas do campo e a necessidade de formação para os professores que atuam nas mesmas (Caldart, 2008; Molina, 2009).

Sua constituição nos remete ao I Encontro Nacional de Educadores/as da Reforma Agrária (I ENERA) ${ }^{13}$ que trouxe à tona para a agenda nacional, mediada pelas práticas educativas, a problemática vivenciada pelos trabalhadores do campo, imposta pelo modelo econômico implantado no Brasil principalmente no final dos anos 1980 e início dos anos de 1990, o neoliberalismo.

O I ENERA, organizado pelo Movimento dos Trabalhadores Sem Terra (MST), foi um momento imprescindível para o surgimento da Educação do Campo, pois possibilitou tornar visível o campo brasileiro com toda sua vida, mas também com toda sua problemática. Podemos dizer que o I ENERA impulsionou a discussão da Educação do Campo, levando os trabalhadores do campo a pensar a necessidade de compreender melhor a realidade rural brasileira e a educação que se fazia/faz presente neste espaço. Por essas características, corroboramos da for- 
mulação de Munarim (2008) quando afirma ser o Manifesto das Educadoras e Educadores da Reforma Agrária ao Povo Brasileiro ${ }^{14}$, resultante desse encontro, a certidão de nascimento do movimento nacional de Educação do Campo, o qual articula diferentes sujeitos coletivos envolvidos nesse processo e gera a organização de encontros mais sistemáticos, como por exemplo, a I Conferência Nacional de Educação Básica do Campo em $1998^{15}$.

É neste processo que se inaugura o termo Educação do Campo, citado no texto básico enviado aos estados para subsidiar os debates preparatórios em vista da I Conferência. Nesta, o termo é legitimado, adquirindo um significado para os movimentos sociais, como destaca Kolling, Nery e Molina:

\begin{abstract}
Utilizar-se-á a expressão campo, e não o mais usual meio rural, com o objetivo de incluir no processo da conferência uma reflexão sobre o sentido atual do trabalho camponês e das lutas sociais e culturais dos grupos que vivem hoje e tentam garantir a sobrevivência desse trabalho. Mas quando se discute a educação do campo se estará tratando da educação que se volta ao conjunto dos trabalhadores e das trabalhadoras do campo, sejam os camponeses, incluindo os quilombolas, sejam as nações indígenas, sejam os diversos tipos de assalariados vinculados à vida e ao trabalho no meio rural (Kolling; Nery; Molina, 1999, p. 29).
\end{abstract}

Destacamos alguns princípios que são essenciais de serem considerados ao tratarmos da especificidade das escolas/classes multisseriadas do campo, a partir da contribuição e acúmulo da Educação do Campo. A ordem em que apresentamos no texto não foi aleatória, embora também não signifique um grau de importância, estando mais vinculada com uma articulação entre os termos apresentados.

O primeiro dos princípios diz respeito à própria função da escola, que é possibilitar o acesso aos conhecimentos historicamente sistematizados, o que denominamos como universais. Entretanto, a Educação do Campo reforça a necessidade da articulação da escola com a vida, outro princípio, o que traz a importância dos conhecimentos da experiência cotidiana, como essenciais para pensar as relações e contradições da produção da vida humana.

Freitas (2010) ao abordar a relação da escola com a vida afirma que o campo tem sua singularidade, assim a escola precisa se conectar com essa vida, para que desde as contradições e os conteúdos da vida presentes nela, possibilite $\mathrm{o}$ acesso à produção cultural mais universal. Assim, ao mesmo tempo em que não se abre mão dos conteúdos clássicos nos termos de Saviani (1996), também se propõe a necessária conexão do trabalho pedagógico com as experiências que as crianças e jovens do campo enfrentam para produzirem suas vidas. Em síntese, o principal fundamento do trabalho pedagógico é a materialidade da vida dos 
educandos, possibilitando que os mesmos se apropriem dos conhecimentos, num processo que se faz colado com sua vida e não apartado da realidade.

Caldart (2008) nos traz o vínculo com as lutas sociais como mais um princípio da Educação do Campo, afirmando ser esta a sua materialidade de origem. Encontra-se imbricado à relação da escola com a vida, uma vez que as comunidades do campo sejam assentamentos, acampamentos, quilombos, de ribeirinhos, ilhéus, possuem uma história comum, que as unificam, por serem todas marcadas historicamente desde o Brasil colônia, pelo enfrentamento e mobilização coletiva. É na luta que se aprende a lutar, e embora essa organização precise acontecer para além da escola, é imprescindível que ela, como agência formativa, esteja inserida nesses processos, possibilitando às crianças, adolescentes e jovens do campo, viverem concretamente a necessidade fundamental da organização para alcançar as conquistas e com isso compreendendo o que significa ser sujeito histórico, vislumbrando a perspectiva da transformação.

Uma matriz ampliada de formação é outro princípio da Educação do Campo, buscando incluir além da socialização dos conhecimentos científicos, também os que dizem respeito às outras dimensões humanas, como as manifestações artísticas, expressivas e corporais. Inter-relacionando com as questões que envolvem o acesso aos conhecimentos universais, a matriz de formação ampla pressupõe que os trabalhadores do campo têm direito ao acesso às manifestações artísticas e culturais que vão desde as produções locais, até as universais. Como exemplo, podemos citar que esta formação precisa ir dos artesões locais, aos clássicos e contemporâneos nas produções das artes visuais.

Por fim, a partir da constatação de que são necessários avanços no conteúdo e na forma da escola, mais um princípio é formulado pela Educação do Campo, o da possibilidade de organização de diferentes tempos e espaços educativos. Imbricado a este, tem-se outro, o que envolve a gestão coletiva e participativa, promovendo tempos e espaços de auto-organização dos estudantes e a constituição de coletivo de educadores. As experiências dos pioneiros da educação russa pós-revolução soviética (de 1917 a 1934), sobretudo a partir das contribuições de Pistrak (2000), além da experiência de Makarenko, à frente da colônia Gorki, são bases que orientam esses princípios assumidos pela Educação do Campo.

Em síntese, tendo em vista o contexto das políticas educacionais neoliberais implementadas no Brasil, a consequente intensificação do processo de nucleação das escolas/classes multisseriadas, ao mesmo tempo em que se propõe uma política governamental de formação específica para os docentes que atuam nesse espaço nos levam a afirmar o estratégico posicionamento de buscar problematizar essa formação na articulação com a Educação do Campo, resultante do acúmulo das 
lutas dos movimentos sociais do campo. Assim, no item seguinte elaboramos as considerações, que buscam para além de fechar as questões, indicar possíveis caminhos no sentido de contribuir para o avanço da formação de docentes das escolas/classes multisseriadas, a partir da incorporação dos princípios da Educação do Campo.

\section{Reflexões sobre a Formação de Professores de Escolas/ Classes Multisseriadas: para concluir?}

Concordamos com D’Agostini, Taffarel e Santos Júnior (2012) quando afirmam, numa crítica ao programa Escola Ativa e na elaboração de uma proposta para melhorar a qualidade do desempenho escolar em classes multisseriadas do campo, que a formação inicial e continuada precisa ser fundamentalmente planejada e executada pelas Instituições de Ensino Superior (IES), sintonizadas com as propostas mais avançadas para a formação de professores, a exemplo da Associação Nacional de Formação de Profissionais da Educação (Anfope), além dos cursos de formação de professores, articulados pelo Programa Nacional de Educação na Reforma Agrária (Pronera) e realizados pelas IES, bem como os demais cursos de Licenciatura em Educação do Campo já existentes no país.

Na crítica ao Escola Ativa, os referidos autores indicam também outro fator relevante, a necessidade de uma fundamentação teórica crítica da educação, permitindo "[...] alterações na prática pedagógica e para a elevação do padrão cultural de professores e estudantes no Brasil" (D’Agostini; Taffarel; Santos Júnior, 2012, p. 320).

Tomamos a liberdade de transpor tal assertiva para a formação de docentes de classes/escolas multisseriadas, assumindo a importância da apropriação teórico-prática da perspectiva da psicologia histórico-cultural, que toma como base os estudos de Vigotski ${ }^{16}$. Um dos conceitos que consideramos essencial para contribuir na discussão sobre a formação docente e a organização do trabalho pedagógico nas classes/ escolas multisseriadas é o de nível de desenvolvimento efetivo, aquele que indica o domínio da criança, demonstrando o que ela já conhece e realiza sozinha. Além dele, o conceito de nível de desenvolvimento iminente ${ }^{17}$, que para Vigotski é "[...] determinado através da solução de problemas -pelas crianças- sob a orientação de um adulto ou em colaboração com companheiros mais capazes" (Vigotski, 1991, p. 97).

Marsiglia (2011) indica uma consequência necessária ao entendimento desses conceitos, ressaltando que o educador precisa realizar seu trabalho pedagógico com seus educandos atuando justamente na zona de desenvolvimento iminente, tornando-o efetivo e avançando “[...] rumo a um maior grau de apropriação do conhecimento, fazendo com a criança e não para ou por ela" (Marsiglia, 2011, p. 37). Nos termos de Scalcon o educador, na perspectiva histórico-cultural, é um "mediador entre o sujeito da aprendizagem e o conteúdo do ensino", um "cria- 
dor da zona de desenvolvimento" (Scalcon, 2002, p. 137), com intencionalidade na sua prática pedagógica, reconhecida como prática social.

Nossa postura teórico-prática ocorre no sentido de buscar compreender como a materialidade vivida nas turmas multisseriadas, com crianças de idades entre 6 e 10 anos, que apresentam diferentes níveis de desenvolvimento efetivo e iminente, podem potencializar, a partir da interação entre professor-aluno, bem como aluno-aluno, os processos de apropriação do conhecimento, estabelecendo uma aprendizagem que se adianta ao desenvolvimento, preceito caro à psicologia histórico-cultural.

Entretanto, isso requer uma sólida formação de docentes que atuam nesses espaços para que, a partir da compreensão dos fundamentos teóricos dessa concepção possam lançar mão de estratégias pedagógicas intencionais que impulsionem a aprendizagem de seus estudantes, garantindo o acesso aos conhecimentos historicamente sistematizados. Nesse sentido, não se abre mão da centralidade do adulto nesse processo, tendo ele a função de planejar, intervir, sistematizar, avaliar e replanejar o trabalho pedagógico, atividades que dizem respeito à especificidade de sua atuação profissional. Entretanto, não se fecham os olhos às possibilidades que as contradições do real trazem ao trabalho do professor, entendendo que nestas podem ser encontradas germens de superação da escola capitalista, ainda que fiquem no plano da luta possível no presente.

Articulada à apropriação da psicologia histórico-cultural, as experiências de organização dos tempos e espaços escolares preconizadas pelos ciclos de formação humana (Freitas, 2003) também são conteúdos significativos ao processo de formação continuada de educadores de classes/escolas multisseriadas. Considerando as críticas a essas experiências, que em grande medida as associam com o construtivismo, o qual possui como fundamento uma concepção teórica antagônica à da psicologia histórico-cultural, a primeira vista poderíamos estar incorrendo numa contradição fundamental. Alguns argumentos podem ajudar a dirimir questionamentos dessa ordem.

Um deles é apresentado por Miranda (2009) ao afirmar que as diversas experiências de implementação de escolas cicladas no país (sejam elas denominadas de ciclos de alfabetização, de aprendizagem ou de formação) não tiveram como justificativa cabal os preceitos psicológicos, não sendo os mesmos determinantes ${ }^{18}$. Outro é demonstrado por Hammel, em seu estudo de uma escola do campo que tem nos ciclos de formação humana sua referência para a organização dos tempos escolares, por "[...] considerar que nas condições reais da sociedade capitalista mexer na estrutura é um elemento importante" e que, portanto, esta opção curricular representa uma das estratégias “[...] para se contrapor a lógica formal e fazer a luta por uma outra sociedade" (Hammel, 2012, p. 14). 
Aliado a esse, a compreensão apontada por Freitas (2003), dos ciclos de formação, que toma como base a necessidade de avançar em experiências educativas que alterem o conteúdo e a forma da escola, é outro argumento que fortalece a perspectiva apresentada. Tal autor toma como base as experiências da pedagogia soviética, afirmando que a escola também ensina relações, "produz a aceitação da vida e a submissão do aluno” e à classe trabalhadora, "[...] continua a sonegar conhecimentos, distribuindo-os quando faz, segundo o nível que é esperado pelas condições gerais de funcionamento do processo de acumulação de riqueza" (Freitas, 2010, p. 156). Tanto a psicologia histórico-cultural, quanto essa concepção de ciclos, tomam como fundamento a teoria do materialismo histórico e dialético, justificando uma vez mais nossa aproximação.

Como concebemos a importância da compreensão dos ciclos de formação para a qualificação do trabalho pedagógico das classes/escolas multisseriadas? Novamente a materialidade se impõe, pois as escolas multisseriadas já trazem concretamente todo o ciclo da infância em uma única turma ${ }^{19}$, além da possibilidade de romper com a lógica excludente e subordinadora da reprovação, como aponta Freitas (2003), uma vez que a criança tende a completar toda a sua escolarização dos anos iniciais do ensino fundamental nessa turma.

Compreendemos que uma formação qualificada, que permita aos educadores que trabalham com essa realidade compreender os fundamentos teóricos já apresentados, os quais tomam como orientação uma concepção teórica crítica da educação, assume uma potencialidade para o avanço das escolas multisseriadas e também nos rumos da Educação do Campo no país.

A elaboração/reformulação dos Projetos Político-Pedagógicos (PPP) das escolas multisseriadas é outro elemento para o fortalecimento da formação docente, entretanto precisa estar articulado à superação do isolamento do trabalho pedagógico, como explicita Barros et al. (2010). Segundo Hage (2010), a solidão do trabalho, o isolamento e o pouco preparo para lidar com a heterogeneidade de idades, séries, ritmos de aprendizagens, entre outras são problemáticas enfrentadas pela unidocência das escolas/classes multisseriadas.

Assim, a constituição de equipes multidisciplinares atuando nas escolas, seja permanentemente ou em forma de rodízio com outras escolas dentro de um mesmo município é uma necessidade, pois além de avançar na afirmação da profissionalização do trabalho docente em turmas multisseriadas, considerando suas especificidades, permite um atendimento de melhor qualidade às crianças e adolescentes, bem como contribui para ações coletivas no espaço escolar.

No âmbito das ações coletivas a elaboração do PPP ganha força na qualificação do trabalho docente, estando articulada com uma formação mais ampla, exigindo parcerias com as IES, no sentido de se 
consolidar como um momento de estudo, pesquisa e reflexão sobre o trabalho pedagógico em turmas multisseriadas, problematizando suas contradições e possibilidades.

A necessidade de planejar com outros pares, a fim de possibilitar trocas e reflexões sobre a prática é também uma necessidade que pode ser superada com a instituição das equipes multidisciplinares. A partir da contribuição de Marsiglia e Martins (2010) compreendemos que o planejamento precisa associar o plano horizontal, que busca articular os conteúdos em longo prazo, perpassando uma etapa, ciclo ou conjunto de séries, com o vertical, aquele que prevê as atividades considerando as possibilidades de desenvolvimento de cada estudante, identificando os conteúdos que especificam, aprofundam e particularizam os conteúdos gerais. Compreendemos este como mais um elemento que tende a contribuir para o avanço na qualidade das classes/escolas multisseriadas.

Por fim, ressalta-se o entendimento de que ao abordar a formação docente para escolas multisseriadas do campo, embora abraçando uma gama de questões, tratamos apenas de um recorte, o mais vinculado com a organização do trabalho pedagógico. Alguns dos fatores que se relacionam com as dificuldades educacionais das escolas/classes multisseriadas são, segundo o INEP a “[...] ausência de uma capacitação específica dos professores envolvidos, a falta de material adequado e, principalmente, na ausência de infraestrutura" (Brasil; INEP, 2007, p. 25). Assim, não menos importante são as condições estruturais dessas escolas, que se articulam às condições de trabalho dos professores do campo, bem como de toda a escola pública brasileira, e por fim, as próprias condições precárias da produção da vida no campo brasileiro. Nesse sentido, retomamos a materialidade de origem da Educação do Campo, colada às lutas dos movimentos sociais do campo por transformações estruturais da sociedade, para afirmar a necessidade dos trabalhadores seguirem lutando coletiva e articuladamente.

Recebido em 19 de março de 2014 Aprovado em 09 de outubro de 2014

\section{Notas}

1 Utilizamos o termo agregando ao termo escolas o de classes, por perceber que coexistem distintas formas de organização de turmas multisseriadas no Brasil, as quais podem envolver a escola como um todo, configurando uma escola multisseriada clássica, sendo esta constituída por uma única turma, com um único professor. Outra opção tem sido a junção de crianças com níveis de escolaridade próximos, por exemplo, do $1^{\circ} \mathrm{e} 2^{\circ}$ anos em uma turma; $3^{\circ}, 4^{\circ}$ e $5^{\circ}$ anos em outra turma, com essa configuração modificando em cada local, a depender da demanda.

2 Tanto o MST quanto o MAB são frutos do processo de modernização conservadora vividos no país a partir da década de 1950. O enfrentamento à expulsão das terras 
e a desapropriações de grandes áreas para o monocultivo bem como para as construções de hidrelétricas no fim dos anos 1970, acarretaram na constituição do Movimento dos Trabalhadores Rurais Sem Terra, que foi fundado em 1984, em Cascavel, PR. Já o MAB se consolidou em abril de 1989, quando foi realizado o "10 Primeiro Encontro Nacional de Trabalhadores Atingidos por Barragens, com a participação de representantes de várias regiões do país". Disponível em: $<$ http://www.mabnacional.org.br>.

3 Ressaltamos que nosso entendimento sobre a relevância da discussão não assume a postura da defesa dessa forma de organização como se ela, por si só, representasse um avanço no campo educacional. A compreensão apresentada no texto parte da leitura da realidade, com a qual constatamos a existências das escolas/classes multisseriadas espalhadas pelo país, atingido a formação e escolarização de parte da classe trabalhadora do campo. Em termos numéricos, o Censo Escolar de 2009 (Brasil; INEP, 2009), aponta a existência de 1,3 milhões de estudantes do ensino fundamental que estudam nas 39.000 escolas ou classes multisseriadas no país. A dimensão continental do Brasil traz essa demanda a qual não pode passar despercebida na luta da classe trabalhadora pelo acesso a uma educação pública, gratuita e de qualidade.

4 Quase em meados da segunda década dos anos 2000 presenciamos um aprofundamento dessas políticas, caracterizadas, segundo Freitas (2012) pelos reformadores empresariais da educação. Uma instância internacional passa a ser chave para compreender a complexidade da situação da educação pública brasileira: a OCDE (Organização para a Cooperação e Desenvolvimento Econômico), organismo ligado diretamente aos empresários e não mais com vínculos com a educação, como a UNESCO e o UNICEF. O Compromisso Todos pela Educação explicita este aprofundamento das políticas neoliberais no país (Freitas, 2012; Evangelista; Leher, 2012). Para Silver (2005) no século XXI, mundialmente a educação passa a ganhar importância como setor de ampliação e recomposição do capital.

5 Em 1990, realizou-se em Jomtien (Tailândia), a Conferência Mundial de Educação para Todos, financiada pela UNESCO (Organização das Nações Unidas para a Educação, Ciência e a Cultura), UNICEF (Fundo das Nações Unidas para a Infância), PNUD (Programa das Nações Unidas para o Desenvolvimento) e Banco Mundial. Dela participaram governos, agências internacionais, organismos não-governamentais, associações profissionais e personalidades destacadas no plano educacional em todo mundo.

$6 \mathrm{Na}$ atualidade o movimento Todos Pela Educação é a prova mais cabal que a sociedade é considerada a principal parceira da instituição escolar quando o assunto é financiamento e fiscalização dos resultados. A atual gestão (2013) é presidida por Jorge Gerdau, dono e presidente da Gerdau, uma das maiores empresas do segmento de aços longos no mundo. Além de seu presidente, todos aqueles que compõem o conselho de governança são empresários, jornalistas, ou pessoas com influência no mercado capitalista.

7 Definem-se os códigos da modernidade como sendo o conjunto de conhecimentos e destrezas necessários para participar da vida pública e desenvolver-se produtivamente na sociedade moderna. Essas capacidades seriam as requeridas para o manejo de aritméticas básicas, a leitura e compreensão de um texto escrito, a comunicação escrita, a observação, descrição e análise crítica do entorno, a recepção e interpretação das mensagens dos meios de comunicação modernos e participação no desenho e execução de trabalho em grupo (Shiroma; Moraes; Evangelista, 2004).

700 Educação \& Realidade, Porto Alegre, v. 40, n. 3, p. 685-704, jul./set. 2015. 
8 Duarte (2006) faz uma crítica a esses pilares destacando suas consequências na educação do país, sendo uma delas o esvaziamento da função social da escola de socialização do conhecimento produzido historicamente pela humanidade aos trabalhadores e seus filhos.

9 Sobre as consequências das pedagogias de competências na formação de um novo sujeito ver Ramos (2001).

10 O Fundo Nacional de Desenvolvimento da Educação (FNDE/MEC), por meio da Diretoria de Projetos Especiais/Fundo de Fortalecimento da Escola (FUNDESCOLA), teve o Programa Escola Ativa entre seus projetos entre 1997 e 2007 (Gonçalves, 2009).

11 Secretaria de Educação Continuada, Alfabetização e Diversidade - SECAD, criada no governo Lula, com a responsabilidade de elaboração e execução de programas e políticas públicas para a Educação do campo, bem como outras especificidades.

12 A adesão dos municípios ao PEA era realizada através do Plano de Ações Articuladas - PAR. As Secretarias Estaduais de Educação eram as responsáveis pelo acompanhamento e monitoramento os municípios que participavam da formação e as universidades pela formação do professores multiplicadores (Gonçalves, 2009).

13 O I ENERA aconteceu no ano de 1997, reunindo educadores e entidades parceiras do MST como Universidade de Brasília - UnB, o Fundo das Nações Unidas para a Infância - UNICEF, a Organização das Nações Unidas para a Educação, Ciência e Cultura - UNESCO e a Conferência Nacional dos Bispos do Brasil - CNBB).

14 Documento elaborado no final do I ENERA que estabelece um conjunto de princípios e compromissos que o MST defende para a educação no contexto da reforma agrária.

15 A I Conferência Nacional Por uma Educação Básica do Campo ocorreu em julho de 1998, em Luiziânia, GO e foi organizada a partir de um desafio assumido ao fim do I ENERA, o de buscar articular as diversas práticas que envolviam as escolas do campo no país.

16 Scalcon (2002) alerta para o trabalho dos colaboradores de Vigotski, Luria e Leontiev, na construção da teoria, ressaltando que a perspectiva histórico-cultural surge originariamente dos estudos realizados pelo soviético Lev Semyonovich Vigotsky. Embora a psicologia soviética assuma diferentes denominações: $p s i$ cologia socio-histórica; corrente socio-histórica da psicologia além de psicologia histórico-cultural, esta última se refere à "[...] teoria em sua totalidade, na qual estão incluídas a psicologia, a literatura, a psicolinguística e as artes, e socio-histórico é o processo pelo qual a teoria passa no decorrer de seu desenvolvimento" (Scalcon, 2002, p. 50).

17 Os termos nível de desenvolvimento efetivo e nível de desenvolvimento iminente são retirados de Marsiglia (2011) em substituição à tradução mais usual: zona de desenvolvimento real e zona de desenvolvimento proximal ou potencial. Para este uso, a autora apoia-se nas críticas acerca da tradução dos textos de Vigotski, elaboradas por Prestes (2010) em sua tese de doutorado.

18 Ainda assim, é importante afirmar que as repercussões práticas podem de fato ter resultado numa flexibilização do saber, decorrente de inúmeros fatores que não nos cabem aprofundar, mas que envolvem a falta de clareza teórica por parte dos educadores que realizaram as experiências cicladas, ou ainda a pró- 
pria defesa do construtivismo como teoria pedagógica que embasou algumas da experiências. Entretanto, reafirma-se, estudos de Miranda (2009) apontam a necessidade de não generalização.

19 Estamos tomando como referência o que consideramos as escolas multisseriadas clássicas, com uma única turma agregando do $1^{\circ}$ ao $5^{\circ}$ ano do Ensino Fundamental, organização esta que corresponde a maioria das escolas multisseriadas no país. Entretanto é preciso registrar que em muitos municípios da região Sul e Sudeste do país, especialmente, já vêm organizando classes compostas pela junção de apenas dois ou no máximo três anos, a depender da demanda de cada local.

\section{Referências}

BARROS, Oscar Ferreira et al. Retratos de Realidade das Escolas do Campo: multissérie, precarização, diversidade e perspectivas. In: ANTUNES-ROCHA, Isabel; HAGE, Salomão Mufarrej (Org.). Escola de Direito: reinventando a escola multisseriada. Belo Horizonte: Autêntica Editora, 2010. P. 399-416.

BRASIL. Instituto Nacional de Pesquisas Educacionais Anísio Teixeira (INEP). Panorama da Educação no Campo. Brasília: INEP, 2007.

BRASIL. Instituto Nacional de Pesquisas Educacionais Anísio Teixeira (INEP). Censo Escolar - 2009. Brasília: INEP, 2009.

BRASIL. Secretaria de Educação Continuada, Alfabetização e Diversidade (SECAD). Projeto Base. Brasília: MEC, 2008.

BRASIL. Secretaria de Educação Continuada, Alfabetização e Diversidade e Inclusão (SECADI). Escola da Terra Leva Formação a Professores de Multisseriadas. 2013. Disponível em: <http://portal.mec.gov.br/index.php?option=com_co ntent\&view=article\&id=19013:escola-da-terra-leva-formacao-a-professores-de-multisseriadas\&catid=211\&Itemid=86>. Acesso em: 03 set. 2013.

CALDART, Roseli Salete. Sobre Educação do Campo. In: SANTOS, Clarice Aparecida dos (Org.). Educação do Campo: campo, políticas públicas, educação. Brasília: INCRA; MDA, 2008. P. 67-86.

CAMPOS, Roselane F. Fazer Mais com Menos: gestão educacional na perspectiva da CEPAL e da UNESCO. In: REUNIÃO ANUAL DA ANPED, 28, 2005, Caxambu. Anais... Caxambu, 2005. P. 01-17.

D’AGOSTINI, Adriana; TAFFAREL, Celi N. Z.; SANTOS JÚNIOR, Cláudio Lira. Escola Ativa. In: CALDART, Roseli Salete; PEREIRA, Isabel Brasil; ALENTEJANO, Paulo; FRIGOTTO, Gaudêncio (Org.). Dicionário da Educação do Campo. São Paulo: Expressão Popular, 2012. P. 313-324.

DUARTE, Newton. O Lema "Aprender a Aprender" nos Ideários Educacionais Contemporâneos. In: DUARTE, Newton. Vigotski e o "Aprender a Aprender": crítica às apropriações neoliberais e pós-modernas da teoria vigotskiana. Campinas: Autores Associados, 2006. P. 51-68.

EVANGELISTA, Olinda; LEHER, Roberto. Todos pela Educação e o Episódio Costin no MEC: a pedagogia do capital em ação na política educacional brasileira. Trabalho Necessário, Rio de Janeiro, n. 15, 2012. Disponível em: <http:// www.uff.br/trabalhonecessario/images/TN1519\%20Artigo\%20Roberto\%20 Leher\%20e\%20Olinda\%20Evangelista.pdf> . Acesso em: 03 set. 2013.

FONSECA, Marília. O Banco Mundial como Referência para a Justiça Social no Terceiro Mundo: evidências do caso brasileiro. Revista da Faculdade de Educação, São Paulo, v. 24, n. 1, p. 37-69, 1998.

702 Educação \& Realidade, Porto Alegre, v. 40, n. 3, p. 685-704, jul./set. 2015. 
FREITAS, Luiz Carlos. Os Reformadores Empresariais da Educação: da desmoralização do magistério público à destruição do sistema público de educação. Educação e Sociedade, Campinas, v. 33, n. 119, p. 379-404, 2012. Disponível em: $<$ http://www.cedes.unicamp.br>. Acesso em: 03 set. 2013.

FREITAS, Luiz Carlos. A Escola Única do Trabalho: explorando os caminhos de sua construção. In: CALDART, Roseli Salete (Org.). Caminhos para Transformação da Escola: reflexão desde práticas da licenciatura em educação do campo. São Paulo: Expressão Popular, 2010. P. 149-162.

FREITAS, Luiz Carlos. Ciclos, Seriação e Avaliação: confronto de lógicas. São Paulo: Moderna, 2003.

GONÇALVES, Gustavo B.; ANTUNES-ROCHA, Maria Isabel; RIBEIRO, Vândiner. Programa Escola Ativa: um pacote educacional ou uma possibilidade para a escola do campo? In: ANTUNES-ROCHA, Maria Isabel; HAGE, Salomão Mufarrej (Org.). Escola de Direito: reinventando a escola multisseriada. Belo Horizonte: Autêntica, 2010. P. 49-60.

GONÇALVES, Gustavo B. Programa Escola Ativa: educação do campo e trabalho docente. 2009. 208 f. Tese (Doutorado em Políticas Públicas e Formação Humana) - Universidade do Estado do Rio de Janeiro, Rio de Janeiro, 2009.

HAGE, Salomão Mufarrej. Escolas Multisseriadas. In: OLIVEIRA, Dalila Andrade; DUARTE, Adriana Cancella; VIEIRA, Lígia Fraga. Dicionário: trabalho, profissão e condição docente. Belo Horizonte: UFMG/Faculdade de educação, 2010. Disponível em: <http://trabalhodocente.net.br/?pg=dicionario-verbetes\&id=279>. Acesso em: 03 set. 2013.

HAMMEL, Ana Cristina. A Organização do Trabalho Pedagógico em Ciclos: análise a partir da Escola Iraci Salete. In: SEMINÁRIO INTERNACIONAL E FÓRUM DE EDUCAÇÃO DO CAMPO DA REGIÃO SUL DO RS: campo e cidade em busca de caminhos comuns, 1, Pelotas, Ed. da UFPEL, 2012. Anais... Pelotas, 2012. Disponível em: <http://www.vanessanogueira.info/sifedoc/>. Acesso em: 03 set. 2013.

KOLLING, Edgar Jorge; NERY, Irmão; MOLINA, Monica C. Por uma Educação Básica do Campo. Articulação Nacional por uma Educação do Campo. Brasília, 1999.

MARSIGLIA, Ana Carolina Galvão. A Prática Pedagógica Histórico-Crítica na Educação Infantil e Ensino Fundamental. Campinas: Autores Associados, 2011.

MARSIGLIA, Ana Carolina Galvão; MARTINS, Lígia. "Programa Escola Ativa”: análise crítica. In: BARBOSA, Maria Valéria; MENDONÇA, Sueli Guadalupe de Lima (Org.). Ensino e Aprendizagem como Processos Humanizadores: propostas da teoria histórico-cultural para a educação básica. Coletânea de textos da 9a Jornada do Núcleo de Ensino de Marília. Marília: Oficina Universitária Unesp, 2010. P. 37.

MIRANDA, Marília Gouvea de. A Organização Escolar em Ciclos e a Questão da Igualdade Substantiva. Revista Brasileira de Educação, Rio de Janeiro, v. 14, n. 40, 2009. Disponível em: <http://www.scielo.br/scielo.php?script=sci_arttext\& pid=S141324782009000100003\&lng=en\&nrm=iso $>$. Acesso em: 03 set. 2013.

MOLINA, Monica C. Educação Popular e Movimentos Sociais: tensões e desafios para a América Latina. In: REUNIÃO ANUAL DA ANPED, 32, 2009, Caxambu. Anais... Caxambu, 2009.

MUNARIM, Antonio. Movimento Nacional de Educação do Campo: uma trajetória em construção. In: REUNIÃO ANUAL DA ANPED, 31, 2008, Caxambu. Anais... Caxambu, 2008. 
PISTRAK, Moisey Mikhaylovich. Fundamentos da Escola do Trabalho. São Paulo: Expressão Popular, 2000.

PRESTES, Zoia Ribeiro. Quando não é a mesma coisa! Análise de traduções de Lev Semionovitch Vigotski no Brasil: repercussões no campo educacional. 2010. 295 f. Tese (Doutorado em Educação) - Universidade de Brasília, Brasília, 2010.

RAMOS, Marise. A Pedagogia das Competências: autonomia ou adaptação? São Paulo: Cortez, 2001.

RIBEIRO, Marlene. Educação do campo e Escola Ativa: contradições na política educacional no Brasil. Educação em Revista, Marília, v. 12, n. 2, p. 23-40, jul./ dez. 2011.

SADER, Emir. Estado e Democracia: os dilemas do socialismo na virada do século. In: SADER, Emir; GENTILI, Pablo (Org.). Pós-Neoliberalismo II: que Estado para que democracia. Petrópolis: Vozes, 1999. P. 120-130.

SANTOS, Fábio J. Souza dos; MOURA, Terciana Vidal. Políticas Educacionais, Modernização Pedagógica e Racionalização do Trabalho Docente: problematizando as representações negativas sobre as classes multisseriadas. In: ANTUNES-ROCHA, Isabel; HAGE, Salomão Mufarrej (Org.). Escola de Direito: reinventando a escola multisseriada. Belo Horizonte: Autêntica Editora, 2010. P. 35-47.

SAVIANI, Demerval. Pedagogia Histórico-Crítica: primeiras aproximações. São Paulo: Cortez/Autores Associados, 1996.

SCALCON, Suze. À Procura da Unidade Psicopedagógica: articulando a psicologia histórico-cultural com a pedagogia histórico-crítica. Campinas: Autores Associados, 2002.

SHIROMA, Eneida O.; MORAES, Maria Célia M.; EVANGELISTA, Olinda. Política Educacional. Rio de Janeiro: DP\&A, 2004.

SILVER, Beverly J. Forças do Trabalho: movimentos trabalhistas e globalização desde 1870. São Paulo: Boitempo, 2005.

VIGOTSKI, Lev Semenovitch. Aprendizagem e Desenvolvimento Intelectual na Idade Escolar. In: VIGOTSKI, Lev Semenovitch; LURIA, Alexander Romanovitch; LEONTIEV, Alexis Nikolaevich. Linguagem, Desenvolvimento e Aprendizagem. São Paulo: Ícone, 1991. P. 80-97.

Natacha Eugênia Janata é doutora em Educação pela Universidade Federal de Santa Catarina, docente do Departamento de Estudos Especializados em Educação da Universidade Federal de Santa Catarina atuando no Curso de Licenciatura em Educação do Campo. Foi professora formadora do Programa Escola Ativa em Santa Catarina no período de 2011 a 2013.

E-mail:natacha.janata@ufsc.br

Edson Marcos de Anhaia é doutorando do Programa de Pós Graduação em Educação pela Universidade Federal de Santa Catarina e mestre em Educação pela mesma instituição. Professor do Departamento de Estudos Especializados em Educação na Universidade Federal de Santa Catarina e docente do Curso de Licenciatura em Educação do Campo-UFSC.

E-mail: edsonanhaia@yahoo.com.br

704 Educação \& Realidade, Porto Alegre, v. 40, n. 3, p. 685-704, jul./set. 2015. 